\title{
ESTADO: SOCIEDADE CIVIL E LUTA HEGEMÔNICA
}

\author{
Ana Maria Said*
}

\begin{abstract}
RESUMO
Procuraremos nesse artigo enfocar a complexa análise de Gramsci ao conceito de "Estado integral", que Christine Buci Gluksmann denomina de "Estado ampliado": sociedade política + sociedade civil, encouraçada de coerção. Para isso, não perderemos de vista a relação dialética entre Estado e sociedade que permeia a obra gramsciana. $\mathrm{Na}$ verdade, ao refletirmos sobre o alcance da obra gramsciana na compreensão do Estado e da luta pelo poder na sociedade contemporânea, não poderemos deixar de pensar o conceito de hegemonia neste pensador que se defronta e confronta com o fascismo e com as tendências autoritárias que incidem sobre a democracia nos tempos atuais.
\end{abstract}

Palavras-chave: Estado. Sociedade civil. Hegemonia. Consenso. Coerção.

\begin{abstract}
We seek in this article to focus on the complex analysis of Gramsci's concept of the "Integral State", which Christine Buci-Gluksmann calls "Extended State": political society + civil society, armored of coercion. For that, we must keep in mind the dialectical relationship between State and society that permeates Gramsci's work. In fact, when we reflect about the scope of Gramsci's work on the understanding of State and the fight of the contemporary society for power, we can't leave behind the concept of hegemony of this thinker, which faces and confronts the fascism and the authoritarian tendencies that affect democracy in current times.
\end{abstract}

Keyword: State. Civil society. Hegemony. Consensus. Coercion.

\footnotetext{
* Doutora em Educação, na área Educação, Sociedade, Política e Cultura pela Universidade Estadual de Campinas - UNICAMP. Professora do Instituto de Filosofia da Universidade Federal de Uberlândia.Email: anasaid@ufu.br
} 
Ao refletir sobre o alcance da obra gramsciana na compreensão do Estado e da luta pelo poder na sociedade contemporânea, não podemos deixar de entender como se torna fundamental a análise do conceito de hegemonia para um pensador que se defronta e confronta com o fascismo. Na verdade, é enfocando a história e a função dos intelectuais que Gramsci desenvolve uma teoria própria de hegemonia e de um novo entendimento do conceito de Estado, como força e como consenso. E, assim, não se pode pensar o conceito de Estado em sua obra, sem a luta contra o fascismo, empreendida por ele, sua principal vítima italiana, assim como a questão que lhe é cara, que lhe infunde esperança: o caminho para a emancipação humana, a criação de uma "nuova civiltà" que supere a "civiltà capitalistica".

Compreender como Gramsci entende a complexidade do conceito de "Estado integral" no capitalismo contemporâneo autoriza-nos pensá-lo como nexo dialético de força e consenso, onde o elemento consenso é o que predomina, sem que, porém, o elemento força desapareça.

Essa passagem do Caderno 4, embora enseje diversas interpretações, oferece uma chave de análise de como há no conceito de Estado, em Gramsci, uma relação orgânica entre sociedade econômica e sociedade política e, assim, entre sociedade civil e sociedade política, uma relação dialética, afirmando que os liberais especulam “(...) sobre a distinção entre sociedade política e sociedade civil e se afirma que a atividade econômica é própria da sociedade civil e a sociedade política não deve intervir na sua regulamentação". Continuando, afirma Gramsci: "Mas, na realidade, esta distinção é puramente metodológica, não orgânica, e na concreta vida histórica, sociedade política e sociedade civil são uma mesma coisa" (GRAMSCI, 1975, p. 460).

Guido Liguori afirma neste sentido que:

É a partir da não separação "ontológica" de Estado e sociedade civil e de política e economia que Gramsci pode captar o novo papel que o político assume no século XX, seja em relação à produção econômica, seja - consequentemente - em relação à composição de classe da sociedade (LIGUORI, 2007, p. 17).

No Caderno 3, ao definir o papel e a função do Estado, Gramsci assevera que: "O Estado moderno abole muitas autonomias das classes 
subalternas (...) mas, que certas formas de vida interna das classes subalternas renascem como partido, sindicato, associação cultural" (GRAMSCI, 1975, p. 303). E, ainda, analisando uma forma de Estado moderno, a "ditadura moderna", ressalta que "abole até mesmo estas formas de autonomia de classe e se esforça por incorporá-las à atividade estatal: ou seja, a centralização de toda a vida nacional nas mãos da classe dominante se torna frenética e absorvente" (GRAMSCI, 1975, p. 303). Sendo mais enfático, no Caderno 25, afirma que: “As ditaduras contemporâneas aboliram legalmente inclusive estas novas formas de autonomia e se esforçam por incorporá-las na atividade estatal: a centralização legal de toda a vida nacional nas mãos do grupo dominante torna-se "totalitária", (GRAMSCI, 1975, p. 2287). É a forma de Estado com a qual Gramsci se defronta, que tenta silenciá-lo, encarcerando-o na marginalidade da prisão fascista.

Gramsci, desenvolvendo o conceito de crise orgânica, no Caderno 13, afirma que quando o grupo social se distingue de seus partidos tradicionais, que foram até então expressão de sua classe ou frações de classe advém uma crise, que pode se tornar perigosa, porque crise de autoridade, que é exatamente uma crise de hegemonia, ou crise do Estado no seu complexo, que pode necessitar de um chefe carismático, já que nenhuma das forças, nem a progressista, nem o grupo conservador, tem a força necessária para a vitória, e "que mesmo o grupo conservador necessita de um patrão" (GRAMSCI, 1975, p. 1604). E, pondera que: "Quando estas crises acontecem, as situações imediatas se tornam delicadas e perigosas, porque o campo é aberto para as soluções de força, para as atividades de potência obscuras representadas por homens providenciais ou carismáticos" (GRAMSCI, 1975, p. 1603).

A tentativa de dominação total é a de calar os indivíduos, destruindo sua individualidade, sua autonomia como pertencimento ao grupo social, o que permite o domínio mais efetivo e indefensável. As vítimas do fascismo (incluindo o nazismo, em uma intensidade ainda maior) sofreram torturas inimagináveis, mas sem dúvida, retirar-lhes o sentido de humanidade foi o que mais agudamente permitiu tanto poder sobre a grande massa que se tornou a população de trabalhadores naquele momento e lugar específicos, a Europa de 1930 e 1940. Porque permitiu a destruição da organização 
política do grupo social subalterno, do sujeito histórico como "vontade coletiva", construída historicamente pelo seu partido.

Mais do que o silêncio imposto à grande massa, o fascismo pretendia impedir o pensar, o viver humano e pleno de sentido, assim como tentaram com a vida e a obra gramsciana. Entretanto, Antonio Gramsci utiliza-se de sua prisão no cárcere fascista para estabelecer um diálogo com seu tempo, de escuridão e pavor, período fecundo de compreensão da luta pelo poder capitalista mais brutal, entremeado por seus longos períodos de febre e delírio, dadas as condições do cárcere fascista, mas de lucidez e resistência ao niilismo humano, apesar das circunstâncias. Período fecundo, inclusive de compreensão do embate de poder que define a sociedade capitalista contemporânea.

As Cartas do cárcere foram, durante o longo período de prisão, a sua voz como resposta à coerção fascista, tentativa de manter-se ativo e ligado à vida humana, mas também, de manter o mundo humano e a sua concretização. Suas cartas nos mostram que ao invés de entregarse ao fatalismo da dureza da vida no cárcere, Gramsci o utiliza para o equacionamento de problemas metodológicos fundamentais do marxismo, principalmente para a tentativa de superar a manipulação total das massas trabalhadoras. É nas Cartas que encontramos uma maior reflexão de Gramsci sobre o fascismo.

Conjugando-se às Cartas, os Cadernos do cárcere representam sua reflexão sobre a possibilidade e a estratégia da organização das massas operárias e camponesas para a superação do capitalismo. No período mais difícil de doença na prisão, quando a tuberculose lhe consumia os pulmões, escreve para Tatiana (maio de 1930): “A minha praticidade consiste nisto: no saber que ao bater a cabeça contra o muro, será a cabeça a se romper, e não o muro" (GRAMSCI, 1996, p. 331). Sua tentativa, ao invés de calar-se frente à situação limite e limitante em que se encontrava, e de dominação da grande maioria das massas trabalhadoras, foi a de pensar em como quebrar a parede e manter a cabeça, ao desenvolver sua concepção de hegemonia para o capitalismo avançado.

Enquanto os Cadernos nos permitem uma compreensão da história contemporânea, com perspectiva humana, as Cartas nos permitem compreender o diálogo com seu tempo, focando a real possibilidade de transformá-lo em momento de realização humana, de resistência. É o que 
impulsionou a figura de um líder operário (através do jornal, L’Ordine Nuovo, do qual era diretor), chefe de um partido da classe operária, a pensar a importância da organização política e do Partido "condottiero" (dirigente) da classe.

O que escreve nas cartas endereçadas a Tatiana (sua cunhada e protetora na prisão), tão retomadas para a compreensão dos escritos gramscianos, sobre a importância dos intelectuais para a transformação histórica (principalmente, a de 19 de março de 1927, cárcere de Milão), afirmando que escrever sobre eles seria sua obra constante, revela o porquê de seu interesse e análise da importância do Partido como intelectual orgânico coletivo, na luta de hegemonias na "sociedade civil", porque, para ele, todos os membros de um Partido devem "ser considerados como intelectuais". Os membros singulares de uma dada classe econômica, quando membros de partido, tornam-se intelectuais, significando intelectuais como construtores do humano.

Sendo assim, em polêmica com Benedetto Croce, que em suas obras define o intelectual como responsável pela reforma intelectual e moral, já que esta representa uma renovação da filosofia da época, desenvolve o conceito de intelectual orgânico diferentemente da visão idealista de intelectual. Define-o com base em sua função de organizador na sociedade, tendo determinado papel de coordenador, já que gerado na organização da produção, nas relações sociais de produção, na direção de classe, a ser empreendida na guerra de posição.

$\mathrm{Na}$ visão idealista e elitista do intelectual, sua relação com a classe operária é um fato ideológico, como em Croce. Para Croce, a única política possível é aquela dos intelectuais, isto é, com a filosofia, com a cultura. Caberia, aos intelectuais e à filosofia, a reforma intelectual e moral, que Gramsci retoma com o embasamento do materialismo histórico. Em Gramsci, a relação é de aquisição de consciência da própria situação nas relações sociais. Contra a concepção de intelectual tradicional que reivindica o status de verdadeiro intelectual, Gramsci contrapõe a criação dos intelectuais orgânicos do proletariado. Escreve:

Uma característica dos intelectuais como categoria social cristalizada (como categoria social que concebe a si mesma como continuação ininterrupta na história, portanto acima da luta dos grupos e não como 
expressão de um processo dialético, pelo qual cada grupo social dominante elabora uma própria categoria de intelectuais) é exatamente de se reunir, na esfera ideológica, a uma precedente categoria intelectual, através de uma mesma nomenclatura de conceitos. Uma nova situação histórica cria uma nova superestrutura ideológica, cujos representantes (os intelectuais) devem ser concebidos como, também esses, "novos intelectuais", nascidos da nova situação e não continuação da precedente intelectualidade (GRAMSCI, 1975, p. 1044).

Na verdade, o intelectual orgânico é o "intelectual coletivo", isto é, o Partido político, nascido da luta de classes, que se efetiva na guerra de posição no capitalismo contemporâneo e avançado, em que surge uma sociedade civil internacional e em que a política se torna hegemonia, e não potência. O que caracteriza o pensamento gramsciano, em sua compreensão da contemporaneidade, é sua análise do cosmopolitismo da vida econômica e o nacionalismo da política.

O americanismo como revolução passiva, vitória da hegemonia burguesa como fordismo, nos EUA, e fascismo, na Europa, comporta o desenvolvimento econômico, por um lado, e a possibilidade da democracia como contradição, por outro, pois representa o fim do Estado-nação. Assim, a luta hegemônica contra o capitalismo passa a desencadear-se como luta pela democracia, na sociedade civil, que de nacional, deve passar para uma democracia internacional, cosmopolita, hegemonia pensada como conceito e como estratégia ${ }^{1}$. Escreve no Caderno 13:

No período posterior a 1870, com a expansão colonial européia, todos estes elementos mudam, as relações organizativas internas e internacionais do Estado se tornam mais complexas e maciças e a formula da "revolução permanente" é elaborada e superada na ciência política na formula de "hegemonia civil". Advém com a arte política aquilo que ocorre na arte militar: a guerra de movimento se torna

1 Esclarecemos que a definição de luta pela democracia em Gramsci, neste sentido, seria a luta da classe dos subalternos para a transformação, a construção de uma nova estrutura econômica, de uma nova organização política e, também, de uma nova orientação ideológica e cultural. 
sempre mais guerra de posição e se pode dizer que um Estado vence uma guerra enquanto a prepara minuciosamente e tecnicamente no tempo de paz. A estrutura maciça das democracias modernas seja como organizações estatais, seja como complexo de associações na vida civil, constituem para a arte política como que "trincheiras" e as fortificações permanentes da fronte na guerra de posição: esses tornam somente "parciais" os elementos do movimento que antes era "toda" a guerra, etc.(...) A questão se põe para os Estados modernos, e não para os países atrasados e para as colônias, onde vigoram ainda as formas que augures são superadas e se tornam anacrônicas. Também a questão do valor das ideologias (...) deve ser estudada em um tratado de ciência política (GRAMSCI, 1975, p. 1566-1567).

Um pouco mais adiante, no mesmo Caderno 13, escreve sobre a passagem da guerra manobrada à guerra de posição, com suas trincheiras e casamatas, comparando-a a guerra de posição no capitalismo avançado:

A mesma redução deve advir na arte e na ciência política, ao menos no que diz respeito aos Estados mais avançados, onde a "sociedade civil" se tornou uma estrutura muito complexa e resistente às "erupções" catastróficas do elemento econômico imediato (crises, depressões, etc.); as superestruturas da sociedade civil são como o sistema das trincheiras na guerra moderna (GRAMSCI, 1975, p. 1615).

O reagrupamento econômico é condição para a transformação da sociedade, mas a realidade de tal transformação é expressa fazendo referência a um termo oposto à estrutura que se pode medir: a transformação social é atuação da ideologia. Essa atuação da ideologia coincide com a transformação do grupo social, de grupo social econômico a sujeito de ação política total, em Partido. E, afirma Nardone,

O Partido, portanto, é uma primeira manifestação do subjetivo que se afirma frente ao objetivo, de vontade política em ato que se une à sua premissa, da realidade (política) que se contrapõe à mera possibilidade. Por este motivo o Partido é o lugar da efetividade histórica e da sua certeza (NARDONE, 1984, p. 71). 
Segundo Gramsci, para a conquista da democracia "pode ser necessário - antes, é quase sempre necessário - um partido fortemente centralizado" (GRAMSCI, 1975, p. 236). Há correntes que atribuem à contingência histórica em que vive Gramsci, o fascismo, o ter desenvolvido uma concepção de partido totalizador, dado o regime totalitário e repressivo em que vivia e a que combatia, dado o confronto entre hegemonias "encouraçadas de coerção", na sociedade civil. Mas, sua compreensão das contradições do capitalismo seguia para muito além do fascismo, embora os totalitarismos signifiquem a possibilidade da classe dominante, em momento de crise orgânica, isto é, crise de hegemonia, ceder a ideologias totalitárias, que representam forças ocultas, momentaneamente abdicando da dominação, até a recuperação do consenso, mantendo, porém, a hegemonia. Também o fordismo é, para ele, uma revolução passiva, como resposta à crise orgânica de seu tempo, esse sim motivo central de sua análise da luta de hegemonias e da concepção de partido. Sobre a democracia nos tempos atuais incidem tendências autoritárias. E todas poderiam ser superadas, pela classe operária organizada politicamente, vencendo a crise de hegemonia que se impõe desde então, na guerra de posições efetuada na sociedade civil.

Para ele, uma crise de hegemonia do capitalismo não pode ser superada sem que se efetue uma radicalização extrema do processo, com a classe dominante, economicamente, tendo que assimilar a si vários grupos sociais, mantendo a direção ético-política, assimilando assim toda a sociedade, sem saturá-la. Se a classe dominada não consegue estar preparada para esse enfrentamento, continuando o processo, modificando-o qualitativamente, se não consegue organizar-se para se contrapor historicamente a essa direção, é a revolução passiva que resultará como horizonte, ao desenvolver o conformismo, ao transformar a função do Estado em "educador", com a continuidade da hegemonia burguesa. Escreve no Caderno 8:

A revolução empreendida pela classe burguesa na concepção do direito e, portanto, na função do Estado, consiste especialmente na vontade de conformismo (portanto, eticidade do direito e do Estado). As classes dominantes precedentes eram essencialmente conservadoras 
no sentido de que não tendiam a elaborar uma passagem orgânica das outras classes às suas, a alargar, isto é, as suas esferas de classe "tecnicamente" e ideologicamente: a concepção de casta fechada. A classe burguesa coloca a si mesma como um organismo em contínuo movimento, capaz de absorver toda a sociedade, assimilando-a ao seu nível cultural e econômico: toda a função do Estado é transformada: o Estado se transforma em "educador", etc. Como advém um fechamento e se retorne à concepção do Estado como pura força, etc. A classe burguesa está "saturada": não só não se difunde, mas se desagrega: não só não assimila novos elementos, mas desassimila uma parte de si mesma (ou ao menos as desassimilações são enormemente mais numerosas que as assimilações). Uma classe que se ponha a si mesma como passível de assimilar toda a sociedade, e seja ao mesmo tempo realmente capaz de exprimir esse processo, leva à perfeição essa concepção do Estado e do direito, a ponto de conceber o fim do Estado e do direito como tornados inúteis por terem exaurido sua tarefa, de estarem absorvidos pela sociedade civil (GRAMSCI, 1975, p. 937).

É o que Gramsci propõe à classe operária (aliada aos outros grupos sociais subalternos), criando seus intelectuais orgânicos, "novos intelectuais": a luta hegemônica, da reforma intelectual e moral, germe de uma "nuova civiltà", resultante das cinzas da sociedade atual. A relação intelectual-classe não é a mesma para a classe burguesa e para a classe subalterna: para a classe burguesa, o intelectual tem uma função direta na constituição dela, já para o partido operário, deve ter uma atuação essencial no processo político de organização política. Gramsci enfatiza a importância de a classe proletária criar seus próprios intelectuais orgânicos, já que não é quem se propõe a sê-lo, que o é, mas aquele que na práxis, se torna um intelectual político do proletariado. Afirma:

Uma das características, mais relevantes, de cada grupo que se desenvolve para o domínio, é a sua luta para a assimilação e a conquista "ideológica" dos intelectuais tradicionais, assimilação e conquista que é tanto mais rápida e eficaz quanto mais o grupo dado elabora simultaneamente os próprios intelectuais orgânicos. (GRAMSCI, 1975, p. 1517). 
Todos os membros de um partido são intelectuais. E é extensa a noção de intelectual para Gramsci, que não se limita à atuação na cultura. Intelectual é também, para ele, a noção de Partido. Este pode dividir-se no mundo moderno, podendo operar como uma força superior aos partidos, já que reconhecida como tal pelo público, pois, segundo ele, um jornal (ou um grupo de jornais), uma revista (ou um grupo de revistas), são também eles "partidos", "frações de partido" ou mesmo "funções de um determinado partido", quando o Estado-Maior intelectual do partido orgânico não pertence a nenhuma das frações em que se dividiu, afirma Gramsci no Caderno 13. Assim como a função de cultura não é só de crítica destrutiva da ideologia dominante, mas deve, também, desenvolver-se como projeto político construtivo, penetração e agregação cultural. No mesmo Caderno, escreve Gramsci: "Que todos os membros de um partido político devam ser considerados como intelectuais, eis uma afirmação, que se pode prestar à brincadeira e à caricatura; porém, se refletirmos, nada de mais exato". (GRAMSCI, 1975, p. 1523).

Em 7 de setembro de 1931, escreve uma carta à Tatiana, desenvolvendo uma concepção do papel dos intelectuais, que não deixa dúvidas quanto à impossibilidade da cisão entre esse conceito e o de hegemonia na compreensão do Estado atual:

(...) Por outro lado, eu estendo, muito, a noção de intelectual e não me limito à noção corrente que se refere aos grandes intelectuais. Este estudo leva inclusive a certas determinações do Estado, que comumente é entendido como Sociedade política (ou ditadura, ou aparelho coercitivo para amoldar a massa popular segundo o tipo de produção e à economia de um dado momento) e não como um equilíbrio da sociedade política com a sociedade civil (ou hegemonia de um grupo social sobre a inteira sociedade nacional exercida através das ditas organizações privadas, como a Igreja, os sindicatos, as escolas, etc.) e, justamente na sociedade civil em especial operam os intelectuais (Benedetto Croce, por exemplo, é uma espécie de papa laico e é um instrumento muito eficaz de hegemonia mesmo que algumas vezes possa encontrar-se em confronto com esse ou aquele governo, etc.) (GRAMSCI, 1996, p. 458-459). 
Em seguida, Gramsci argumenta nesta mesma carta, que o governo de uma classe econômica que não sabe criar a própria categoria de intelectuais e, assim, exercitar uma hegemonia, para além do poder de ditadura, não consegue manter a dominação. Assim deve ser também a organização da luta pelo poder da classe assalariada (ou de subalternos como ele denomina), uma luta para além de ditadura, empreendida nas organizações privadas da sociedade civil. O próprio exemplo que toma, o de Benedetto Croce como instrumento muito eficaz de hegemonia da classe dominante, mesmo que se confronte aqui e ali com alguns governos, como foi com o governo fascista, demonstra a importância da criação dos próprios intelectuais, como hegemonia de um grupo social sobre a inteira sociedade nacional, através dos aparelhos privados.

Quando Gramsci utiliza a expressão: "organizações, ditas privadas", enfatiza-se que essas organizações, na verdade, fazem parte do Estado, permitindo-nos falar, então, de Estado ampliado, embora o termo que utilize nos Cadernos, seja o de Estado integral. No Caderno 6, irá utilizar a expressão "Estado em sentido orgânico e mais amplo" (GRAMSCI, 1975, p. 763). Na verdade, podemos pensar que as organizações chamadas privadas, por Gramsci, que formam o consenso, estão articulados dialeticamente ao Estado, o que nos proporciona a possibilidade de pensar morfologicamente o poder na sociedade contemporânea, poder hegemônico, longe de propiciar uma interpretação idealista.

É interessante ressaltar como as conquistas democráticas modernas asseguraram direitos civis e políticos à classe assalariada e aos subalternos, que se impõem às revoluções passivas. Conquistas duramente adquiridas nas lutas das organizações sociais da classe trabalhadora, como os direitos de cidadania. As revoluções passivas significam, na luta hegemônica empreendida na sociedade civil, em momentos de crise orgânica do sistema capitalista, como a que vivemos hodiernamente, a vitória da hegemonia da classe proprietária, isto é fato. Porém, as conquistas democráticas e civis das classes subalternas, nas lutas de hegemonia na sociedade burguesa, significam um avanço na guerra de posição empreendida por esses grupos, e possibilidades reais de avanço na luta hegemônica. Podemos afirmar que dentro do próprio sistema se engendra a possibilidade real de transformação social, com caminhos para uma sociedade regulada, fim da luta de classes, como contradição do sistema. Possibilidade de um Estado ético e de cultura? No Caderno 8, afirma Gramsci a esse propósito: 
Parece-me que o que de mais sensato e concreto se possa dizer a propósito do Estado ético e de cultura é isso: cada Estado é ético enquanto uma das suas funções mais importantes é aquela de elevar a grande massa da população a um determinado nível cultural e moral, nível (ou tipo) que corresponde às necessidades de desenvolvimento das forças produtivas e, portanto, aos interesses da classe dominante. A escola como função educativa positiva e os tribunais como funções educativas e negativas, são as atividades estatais mais importantes em tal sentido: mas na realidade no final desdobram uma multiplicidade de outras iniciativas e atividades ditas privadas, que formam o aparato da hegemonia política e cultural das classes dominantes.(...) Mas, na realidade, somente o grupo social que põe o fim do Estado e de si mesmo como o fim a se atingir pode criar um Estado ético, que tende a por fim às divisões internas dos dominados, etc., e a criar um organismo social unitário técnico-moral (GRAMSCI, 1975, p. 10491050).

Não podemos separar os aspectos de força e consenso presentes no Estado, dialeticamente, para compreendermos como chegar ao poder hegemônico da classe subalterna, que deve tornar-se sujeito histórico, tornando-se Estado, para fazer definhar o aspecto da força.

A grande questão posta à contemporaneidade, aos intelectuais de "tipo novo", reflete a crise dos partidos e de suas funções na luta hegemônica. Pressiona a apreender o confronto de hegemonias na sociedade civil, palco da luta pela transformação, assim como possibilidade de construção de uma nova sociedade, do Estado ético. De qualquer modo, o que nos instiga a continuar pensando a necessidade da organização política é o entendimento, central em Gramsci, do processo de criação de uma "vontade coletiva", função do sujeito histórico como luta coletiva, na guerra de posição, travada hodiernamente na sociedade civil, para atingirmos uma sociedade de vida humana integral, possível de ser definida como tal. Isso implica convicção de que a luta será travada pelo otimismo da vontade, suplantando o pessimismo da razão. Mas, principalmente, que deve ser travada nas trincheiras da sociedade civil, para transformá-la e eliminar dela o momento da força. 


\section{Referências}

BUCI-GLUCKSMANN, C. Gramscie lo Stato: per una teoria materialistica della filosofia. Roma: Editori Riuniti, 1976.

CROCE, B. Cultura e vita morale. Napoli: Bibliopolis, 1993.

FERRI, F.(Org.). Política e storia in Gramsci. Roma: Ed. Riuniti \& Istituto Gramci, 1977.

GRAMSCI, A. Quaderni del carcere: A cura di Valentino Gueratana. 2. ed.,. Edizione Critica dell'Istituto Gramsci. Torino: Ed. Einaudi, 1975.v. $1,2,3$ e 4 .

. Cartas do cárcere. Organização de Antonio A. Santucci. Palermo: Ed. Sellerio, 1996.

IZZO, F. Democrazia e cosmopolitismo in Antonio Gramsci. Roma: Carocci Ed., 2009.

LIGUORI, G. Roteiros para Gramsci. Rio de Janeiro: Editora UFRJ, 2007.

MUSCATELLO, B. (Ed.). Gramsci e il marxismo contemporaneo. Tradução de Roberto Della Seta. Roma: Ed. Riuniti, 1990.

NARDONE, G. Il pensiero di Gramsci. Bari: De Donato, 1984.

VACCA, G. Vida e pensamento de Antonio Gramsci (1926-1937). Brasília: Fundação Astrojildo Pereira; Rio de Janeiro: Contraponto, 2012.

Data de registro: $10 / 03 / 2014$ Data de aceite: $23 / 04 / 2014$ 